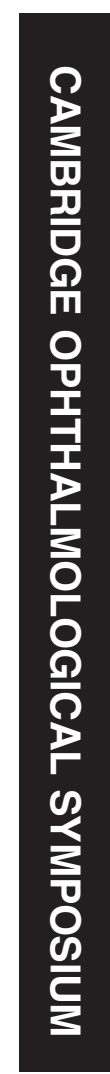

${ }^{1}$ Brien Holden Vision Institute, Sydney, Australia

${ }^{2}$ Vision Co-operative Research Centre, Sydney, Australia

${ }^{3}$ School of Optometry and Vision Science, University of New South Wales, Sydney, Australia

${ }^{4}$ College of Optometry, University of Houston, Houston, TX, USA

${ }^{5}$ Private Practice, Berkeley, CA, USA

${ }^{6}$ Zhongshan Ophthalmic Centre, Sun-Yet Sun University, Guangzhou, China

Correspondence: B Holden, Brien Holden Vision Institute, Level 4, Rupert Myers Building, Gate 14, Barker

Street, Kensington, NSW 2052 Australia.

Tel: +6129385 7517;

Fax: +61 293857401

E-mail: b.holden@

brienholdenvision.org

Received: 30 September 2013 Accepted: 15 October 2013 Published online: 20 December 2013

\section{Myopia, an underrated global challenge to vision: where the current data takes us on myopia control}

\begin{abstract}
Myopia is the most frequent cause of distance impairment in the world and is creating an alarming global epidemic with deleterious ramifications for the quality of life and economic health of individuals and nations as a whole. In addition to being immediately disadvantageous, myopia increases the risk of serious disorders such as myopic macular degeneration, retinal detachment, glaucoma, and cataract and is a leading cause of visual impairment and blindness across many countries. The reduction in age of onset of myopia is of great concern since the earlier the onset, the more myopic the individual will become, with all the attendant increased risks of accompanying debilitating eye conditions. The economic burden is great; both in consequences of uncorrected refractive error and also in the provision of devices for correcting visual acuity. Earlier onset of myopia increases the lifetime economic burden related to loss of productivity and independence, leading to a reduced quality of life. Recent data suggest addressing accommodation per se has little direct amelioration of myopia progression. Pharmacological interventions that effect changes in the sclera show promising efficacy, whereas optical interventions based on a myopic shift in the retinal image are proving to effect up to $55 \%$ reduction in the rate of progression of myopia. Early contact lens and spectacle interventions that reduce the rate of progression of myopia are able to significantly reduce the burden of myopia. These nonpharmacological interventions show profound promise in reducing the overall associated morbidity of myopia.
\end{abstract}

B Holden 1,2,3, P Sankaridurg ${ }^{1,2,3}$, E Smith ${ }^{2,4}$, T Aller $^{2,5}, \mathrm{M} \mathrm{Jong}^{1}$ and $\mathrm{M} \mathrm{He}^{6}$
Eye (2014) 28, 142-146; doi:10.1038/eye.2013.256; published online 20 December 2013

Keywords: blindness; myopia; myopia control; vision impairment

Prevalence of myopia and high myopia

On the basis of world-wide prevalence of myopia, it can be estimated that over $22 \%$ of the current world population, that is, 1.5 billion people are myopic, and although myopia has often been referred to as a 'simple' refractive error, even in lower amounts it enhances the risk of serious eye disorders such as retinal detachment, cataract, and glaucoma. More urgently perhaps, high myopia is emerging as the major cause of blindness in some Asian countries. For example, myopic macular degeneration (MMD) is now the major cause of permanent monocular blindness in Japan and of new cases of blindness in Shanghai. ${ }^{1,2}$ On a wider front affecting over 100 million children, adults and elderly people with massive socio-economic consequences, uncorrected myopia is the most frequent cause of distance visual impairment in the world. ${ }^{3}$

The prevalence of myopia is rising dramatically, reaching 70-80\% in many East Asian countries and $\sim 25-40 \%$ in Western countries; ${ }^{4-11}$ and high myopia (defined as greater than $-6.00 \mathrm{D}$ ) ranges from 6.8 to $38 \%$ in Asia. ${ }^{8,12-15}$ In the United States, myopia has doubled in the last 30 years $^{6}$ and the prevalence of myopia over $8.00 \mathrm{D}$ has risen eightfold. In China where there are $\sim 216$ million individuals in the age range of $15-24$ years $^{16}$ and with a prevalence of myopia in young adults aged 
15-25 years of over $75 \%$, it is estimated that there are at least 160 million young myopes and 16 million with myopia over $-6.0 \mathrm{D}$. The shift to a younger onset of myopia is especially worrying as younger eyes experience more rapid progression of myopia which could lead to even greater levels of high myopia than those currently being reported.

\section{Blindness due to myopia}

The retinal abnormalities identified and associated with myopia include chorioretinal atrophy, lattice degeneration, pigmentary degeneration, lacquer cracks, posterior staphyloma, Fuch's spot, macular degeneration, retinal breaks and detachment, and posterior vitreous detachment. ${ }^{17-20}$ These degenerative changes substantially increase the risk of loss of vision and indeed in countries where the prevalence of myopia is high, MMD has been identified as one of the leading causes of visual impairment and blindness. MMD was the most frequent cause of visual impairment and blindness in a population of elderly Chinese in Taiwan ${ }^{21}$ and a pilot assessment of Hong Kong Chinese residents aged 40 and over found myopic choroidal degeneration to be the leading cause for impaired vision $(<20 / 60$ visual acuity). ${ }^{22}$ Similarly, in a cross-sectional study conducted in Tajimi City, Japan, the primary cause for blindness was MMD. ${ }^{1}$ Interestingly, even in western populations wherein the prevalence of myopia is less, MMD was frequently found to be a significant cause of visual impairment and blindness. The Copenhagen study found myopia-related retinal disorders to be the most common cause of impaired vision with MMD being the third most common cause of blindness. ${ }^{23}$ The Rotterdam eye study ${ }^{24}$ found that in persons younger than 75 years, myopic degeneration was the most important cause of impaired vision. ${ }^{24}$ And in a more recently conducted, Los Angeles Latino Eye Study, myopic degeneration was the third most major cause of blindness. ${ }^{25}$

In addition to retinopathy, increasing levels of myopia is said to increase the risk of a number of other ocular pathologies. The association between glaucoma and myopia has been reported across multiple, large, population-based studies involving many ethnicities with the odds of developing glaucoma rising with increasing myopia. The Blue Mountains Eye Study reported an odds ratio of 2.3 for low myopia and 3.3 for moderate-to-high myopia $(\geq-3.0 \mathrm{D}){ }^{26}$ A systematic review of 11 population-based cross-sectional studies found the pooled odds ratio of the association between low myopia (up to $-3.0 \mathrm{D}$ ) and glaucoma to be 1.65 and for myopia $>-3.0 \mathrm{D}$ to be $2.46 .{ }^{27}$ As with glaucoma, the link between cataract and myopia has been reported across many studies. A meta-analysis of large, population-based studies found myopia to be associated with nuclear as well as posterior subcapsular cataracts. ${ }^{28}$ Also, it has been reported that myopic eyes have an increase in optic disc abnormalities such as optic nerve crescents, tilted discs, and larger disc areas. ${ }^{17,29}$

\section{Economic burden}

For each and every individual with myopia, there are the economic or financial considerations with both uncorrected refractive error and the cost of treatment of the condition with optical devices or other refractive modalities and the need for frequent and long-term management of the condition by the eye-care practitioner. The earlier the onset of myopia, the greater is this burden extending over many years and possibly over the lifetime of the individual. The long-term management not only includes the need to monitor the eye for any refractive error change but to also monitor the eye for risks associated with high levels of myopia. At a stage where myopia progresses and is categorised to be high myopia, additional economic and health burdens are imposed due to more frequent visits and complex corrective strategies. In addition, in highly myopic eyes, even in the absence of retinal pathology or degeneration, visual performance is frequently found to be reduced and imposes a burden not dissimilar to those seen in eyes with significant visual impairment resulting in loss of productivity, quality of life, and independence.

Even without obvious retinal pathology, and in spite of attempts to fully correct the condition, the quality of vision as indicated by best-corrected visual acuity is compromised in highly myopic eyes. One reason for reduced vision is spectacle minification resulting in loss of resolution. Other reports have proposed that increased eye length contributing to retinal stretching and spacing of the cone mosaic, morphologic changes in the photoreceptor outer segment, ${ }^{30-32}$ and decreased subfoveal choroidal thickness delivering less oxygen and nutrients to outer retina may have a role. ${ }^{33}$ Also, it was reported that there appeared to be a correlation between degree of myopia at age 14 and subsequent visual loss. ${ }^{34}$

Clearly either loss of functional vision associated with uncorrected refractive error or permanent vision loss significantly affect all aspects of the individual's life. And at a stage where myopia causes significant visual impairment and blindness, the constraints experienced by affected individuals are likely to be different to those with functional vision, and is likely to further limit their choices in life and pose additional monetary and physical burden. ${ }^{35}$ In addition to direct costs, there are a significant burdens imposed due to the decrease in productivity, loss of quality of life, and independence 
among those affected that translates to a significant health and socio-economic burden for the society.

Given the evidence that the number of eyes destined to become highly myopic is increasing along with the substantial burdens associated with the condition, the need to reduce the number of eyes becoming highly myopic is urgent.

\section{Current data on myopia control and where it takes us}

Pharmacological, environmental, and optical interventions have been used to try to slow the progress of myopia. Often these have been aimed at controlling accommodative responses, however, accommodation appears to have a very minor role, if any, in the induction of myopia.

Recent evidence suggests that atropine, a most effective pharmacological agent, slows the progress of myopia through non-accommodative mechanisms, acting directly on receptors in the sclera. ${ }^{36}$ More recently the pharmacological agent, 7-methylxanthine (7MX), has been reported to be able to reduce the rate of progress of myopia in compliant children by $66 \%$ with a daily $400 \mathrm{mg}$ capsule and is said to act by causing scleral collagen thickening and proliferation without side effects. ${ }^{37}$

\section{Optical intervention}

A most promising method of myopia control is the animal and human optical intervention clinical trials based on creating a myopic shift in the retinal image in the peripheral retina that slows the development and progress of myopia. Many forms of optical intervention, sometimes combined with temporary reductions in myopia due to altering corneal shape such as with orthokeratology, are aimed at slowing myopia by reducing relative peripheral hyperopia. Such a simple, non-invasive intervention that acts merely by changing the image profile provides a 'natural' stimulus which seems not to create rebound effects unlike pharmacological agents that act directly on tissue systems. These optical strategies appear to slow the progression of myopia by $30-55 \%$ and without adverse effects. ${ }^{38-42}$ It has been suggested that reducing the progression of myopia by as little as $33 \%$ would reduce the number of highly myopic eyes $(>-5.00 \mathrm{D})$ by as many as $75 \%{ }^{43}$ Data from a longer term clinical study, involving the use of contact lenses to reduce the hyperopic defocus at the peripheral retina, showed that the ability of these lenses to slow the progression of myopia was a consistent $40 \%$ per year over the study period of 43 months. ${ }^{44}$

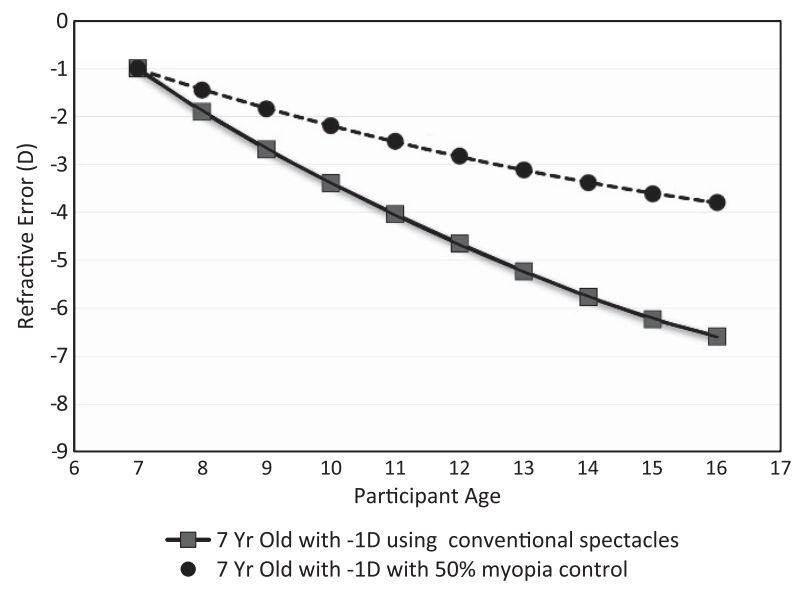

Figure 1 Myopia progression for a 7-year-old child with conventional correction based on experimental data and progress with a myopia control contact lens that slows the rate of myopia increase by $50 \%$ per year.

\section{Summary}

One new therapeutic preparation (7MX) is interesting, although it needs a long-term clinical trial concentrating on efficacy over time and possible side effects. Orthokeratolgy has been shown to produce an average reduction in the rate of progress of myopia of $30 \%$ by inducing a flat-centre, steeper periphery hyperopiareducing corneal shape in a 5-year study with a decreased effect during the fourth and fifth year. Optical intervention with strategies focussed on reducing peripheral hyperopia, has proven in its many forms from executive bifocal spectacles to peripheral plus soft contact lenses, to be capable of $30-55 \%$ reductions in the rate of progress of myopia and in one study with a consistent reduction of $\sim 40 \%$ each year over 3.5 years.

If the rate of increase of myopia could be consistently reduced by $50 \%$ per year, then using the Sankaridurg and Holden evidence-based model for rate of myopia increase for an Asian population (see publication by Sankaridurg and Holden in the same issue), as shown in Figure 1, the effect on high myopia prevalence and its associated morbidity could be profound. Clearly one way forward is the large-scale implementation of optical intervention strategies that create an effective myopia-controlling relative image profile. The refinement, adoption, and widespread use of contact lens, spectacle-based and selective pharmacological myopia control strategies could have massive beneficial outcomes for hundreds of millions of future myopes.

\section{Conflict of interest}

The authors have patents on myopia control strategies. 


\section{Acknowledgements}

The work is supported by grants from the Australian Federal Government through the Cooperative Research Centres scheme and the Brien Holden Vision Institute.

\section{References}

1 Iwase A, Araie M, Tomidokoro A. Tajimi Study Group. Prevalence and causes of low vision and blindess in a Japanese adult population: the Tajimi study. Ophthalmology 2006; 113: 1354-1362.

2 Wu L, Sun X, Zhou X, Weng C. Causes and 3 year incidence of blindness in Jing-An District, Shanghai, China 2001-2009. BMC Ophthalmol 2011; 11: 10

3 Resnikoff S, Pascolini D, Mariottia SP, Pokharel GP. Global magnitude of visual impairment caused by uncorrected refractive errors in 2004. Bull World Health Organ 2008; 86: 63-70.

4 Lin LL, Chen CJ, Hung PT, Ko LS. Nation-wide survey of myopia among schoolchildren in Taiwan, 1986. Acta Ophthalmol Suppl 1988; 185: 29-33.

5 Lin LL, Shih YF, Hsiao CK, Chen CJ. Prevalence of myopia in Taiwanese schoolchildren: 1983 to 2000. Ann Acad Med Singapore 2004; 33: 27-33.

6 Vitale S, Sperduto RD, Ferris FL 3rd. Increase prevalence of myopia in the United States between 1971-9172 and 1999-2004. Arch Ophthalmol 2009; 127: 1632-1639.

7 Kempen JH, Mitchell P, Lee KE, Tielsch JM, Broman AT, Taylor HR et al. The prevalence of refractive errors among adults in the United States, Western Europe and Australia. Arch Ophthalmol 2004; 122(4): 495-505.

8 Sun J, Zhou J, Zhao P, Lian J, Zhu H, Zhou Y et al. High prevalence of myopia and high myopia in 5060 Chinese University students in Shanghai. Invest Ophthalmol Vis Sci 2012; 53: 7504-7509.

9 He M, Zeng J, Liu Y, Xu J, Pokharel GP, Ellwein LB. Refractive error and visual impairment in urban children in southern China. Invest Ophthalmol Vis Sci 2004; 45: 793-799.

10 He M, Huang W, Zheng Y, Huang L, Ellwein LB. Refractive error and visual impairment in school children in rural southern China. Ophthalmology 2007; 114: 374-382.

11 Saw SM, Carkeet A, Chia KS, Stone RA, Tan DT. Component dependent risk factors for ocular parameters in Singapore Chinese children. Ophthalmology 2002; 109: 2065-2071.

12 Lee JH, Jee D, Kwon JW, Lee WK. Prevalence and risk factors for myopia in a rural Korean population. Invest Ophthalmol Vis Sci 2013; 54: 5466-5471.

13 Pan CW, Zheng YF, Anuar AR, Chew M, Gazzard G, Aung $T$ et al. Prevalence of refractive errors in a multiethnic Asian population: the Singapore epidemiology of eye disease study. Invest Ophthalmol Vis Sci 2013; 54: 2590-2598.

14 Jung SK, Lee JH, Kakizaki H, Jee D. Prevalence of myopia and its association with body stature and educational level in 19-year-old male conscripts in seoul, South Korea. Invest Ophthalmol Vis Sci 2012; 53: 5579-5583.

15 Wang TJ, Chiang TH, Wang TH, Lin LLK, Shih YF. Changes of the ocular refraction among freshman in National Taiwan University between 1988 and 2005. Eye 2009; 23: 1168-1169.

16 China Demographics Profile 2013. http:/ / www.indexmundi. com/china/demographics_profile.html.

17 Chang L, Pan CW, Ohno-Matsui K, Lin X, Cheung GC, Gazzard G et al. Myopia-related fundus changes in
Singapore adults with high myopia. Am J Ophthalmol 2013; 155: 991-999.

18 Vongphanit J, Mitchell P, Wang JJ. Prevalence and progression of myopic retinopathy in an older population. Ophthalmology 2002; 109: 704-711.

19 Liu LL, Xu L, Wang YX, Wang S, You QS, Jonas JB. Prevalence and progression of myopic retinopathy in Chinese adults: the Beijing Eye Study. Ophthalmology 2010; 117: $1763-1768$.

20 Pierro L, Camesasca FI, Mischi M, Brancato R. Peripheral retinal changes and axial myopia. Retina 1992; 12: 12-17.

21 Hsu WM, Cheng JH, Liu JH, Tsai SY, Chou P. Prevalence and causes of visual impairment in an elderly Chinese population in Taiwan: the Shihpai Eye Study. Ophthalmology 2004; 111: 62-69.

22 Van Newkirj MR. The Hong Kong vision study: a pilot assessment of visual impairment in adults. Trans Am Ophthalmol Soc 1997; 95: 715-749.

23 Buch H, Vinding T, la Cour M, Appleyard M, Jensen GB, Nielsen NV. Prevalence and causes of visual impairment and blindness among 9980 Scandinavian adults. The Copenhagen city eye study. Ophthalmology 2004; 111: 53-61.

24 Klaver CC, Wolfs RCW, Vingerling JR, Hofman A, de Jong PTVM. Age-specific prevalence and causes of blindness and visual impairment in an older population. The Rotterdam study. Arch Ophthalmol 1998; 116: 653-658.

25 Cotter SA, Varma R, Ying-Lai M, Azen SP, Klein R. Los Angeles Latino Eye Study Group. Causes of Low Vision and Blindness in adult Latinos. Ophthalmology 2006; 113: 1574-1582.

26 Mitchell P, Hourihan F, Sandbach J, Wang JJ. The relationship between glaucoma and myopia: the Blue Mountains Eye Study. Ophthalmology 1999; 106: 2010-2015.

27 Marcus MW, de Vries MM, Montolio J, Jansonius NM. Myopia as a risk factor for open-angle glaucoma: a systematic review and meta-analysis. Ophthalmology 2011; 118: 1989-1994.

28 Pan CW, Cheng SY, Saw SM, Wang JJ, Wong TY. Myopia and age-related cataract: a systematic review and meta-analysis. Am J Ophthalmol 2013; 156(5): 1021-1033.e1.

29 Samaramawickrama C, Mitchell P, Tong L, Gazzard G, Lim L, Wong TY et al. Myopia-related optic disc and retinal changes in adolescent children from Singapore. Ophthalmology 2011; 118: 2050-2057.

30 Kitaguchi Y, Bessho K, Yamaguchi T, Nakazawa N, Miahsi T, Fujikado Tl. In vivo measurements of cone photoreceptor spacing in myopic eyes from images obtained by an adaptive optics fundus camera. Jpn J Ophthalmol 2007; 51: 456-461.

31 Chui TY, Song H, Burns SA. Individual variations in human cone photoreceptor packing density: variations with refractive error. Invest Ophthalmol Vis Sci 2008; 49: 4679-4687.

32 Coletta NJ, Watson T. Effect of myopia on visual acuity measured with laser interference fringes. Vision Res 2006; 46: 636-651.

33 Nishida F, Fujiwara T, Imamura Y, Lima LH, Kurosaka D, Spaide RF. Choroidal thickness and visual acuity in highly myopic eyes. Retina 2012; 32(7): 1229-1236.

34 Goldschmidt E, Fledelius H. High myopia progression and visual impairment in a non selected group of Danish 14 year olds followed over 40 years. Optom Vis Sci 2005; 82(4): 239-243. 
35 Frick KD. What the comprehensive economics of blindness and visual impairment can help us understand. Indian J Ophthalmol 2012; 60(5): 406-410.

36 McBrien NA, Moghaddam HO, Reeder AP. Atropine reduces experimental myopia and eye enlargement via a nonaccommodative mechanism. Invest Ophthalmol Vis Sci 1993; 34: 205-215.

37 Trier K, Munk Ribel-Madsen S, Cui D, Brogger Christensen S. Systemic 7-methylxanthine in retarding axial eye growth and myopia progression: a 36 month pilot study. J Ocul Biol Dis Infor 2008; 1: 85-93.

38 Anstice NS, Phillips JR. Effect of dual focus soft contact lens wear on axial myopia progression in children. Ophthalmology 2011; 118(6): 1152-1161.

39 Sankaridurg P, Holden B, Smith 3rd, E, Naduvilath T, Chen X, de la Jara PL et al. Decrease in rate of myopia progression with a contact lens designed to reduce relative peripheral hyperopia: one year results. Invest Ophthalmol Vis Sci 2011; 52(13): 9362-9367.
40 Sankaridurg P, Donoval L, Varnas S, Ho A, Chen X, Martinez A et al. Spectacle lenses designed to reduce progression of myopia: 12 month results. Optom Vis Sci 2010; 87(9): 631-641.

41 Hiroaka T, Kakita T, Okamoto F, Takahashi H, Oshika T. Long term effect of overnight orthokeratology on axial length elongation in childhood myopia: a 5-year follow-up study. Invest Ophthalmol Vis Sci 2012; 53(7): 3913-3919.

42 Cheng D, Schmid KL, Woo GC, Drobe B. Randomized trial of effect of bifocal and prismatic bifocal spectacles on myopic progression: two year results. Arch Ophthalmol 2010; 128(1): 12-19.

43 Brennan N. Predicted reduction in high myopia for various degrees of myopia control. Poster presentation, The British Contact Lens Association 2012.

44 Holden BA, Sankaridurg PR, de la Jara P, Naduvilath T, Ho A, Sweeney DF et al. Decreasing peripheral hyperopia with distance centre relatively plus powered periphery contact lenses reduced the rate of progress of myopia: A 5 year Vision CRC study. E Poster 6300, ARVO 2012. 